\title{
Study on bacterial contamination in hot trend street food - milk tea
}

\author{
Thanh Tran ${ }^{1,2, *}$, Pham Hoang Khoi ${ }^{2}$, Vo Minh Tran ${ }^{3}$, Tran Thi Bich Phuong ${ }^{3}$, Le Thi Hong \\ Tuyet $^{3}$, Van Doan $\mathrm{Thi}^{4}$, and Loc Huu $\mathrm{Ho}^{5}$ \\ ${ }^{1}$ Institute of Environmental Sciences, Nguyen Tat Thanh University, Ho Chi Minh City, Vietnam \\ 2 Faculty of Food and Environmental Engineering, Nguyen Tat Thanh University, Ho Chi Minh City, \\ Vietnam \\ ${ }^{3}$ Faculty of Environmental, Ho Chi Minh City University of Natural Resources and Environment, Ho \\ Chi Minh City 70000, Viet Nam. \\ ${ }^{4}$ Faculty of Biology and Environmental Science, The University of Education, Danang, Vietnam \\ ${ }^{5}$ Water and Engineering Management, Asian Institute of Technology, Pathum Thani, Thailand.
}

\begin{abstract}
The safety and presence of pathogenic microorganisms in street foods are attracting special attention from consumers. Milk tea (bubble tea) is a hot trend that is most popular among young people in street food in Southeast Asia. In this study, the method of surveying and quantifying Ecoli - Coliform in milk tea samples was combined to assess microbial contamination status and assess the opinion of students. Initial results show the existence of pathogenic microorganisms Ecoli and Coliform in milk tea with the significantly different level of contamination between milk tea with the well-known brand (brand name) and no brand name (no brand name). The survey results show that consumers and students, in particular, have a very high level of spending on milk tea and are very concerned about food safety and hygiene in milk tea. However, the information and understanding on food safety and foodborne pathogens are minimal.
\end{abstract}

\section{Introduction}

The world is facing the current era of industrialization and modernization, food safety and hygiene is always the top concern of society. There are many causes of food poisoning, such as chemicals in raw materials, pathogenic microorganisms, the nature of food containing some toxins. According to statistics from the Food Safety Department of the Ministry of Health, Vietnam has about 250-500 cases of food poisoning with 7,000-10,000 victims and 100-200 deaths annually [1]. The cause was determined to come from food contaminated with microorganisms $(33 \%)$, food contaminated with chemicals $(27 \%)$, food containing natural toxins $(37.5 \%)$, feed contaminated with pesticides (high concentration spray, not isolated from harvest date), or additives (borax, industrial color, chemical sugar) with high toxic residues [2]. However, food safety and hygiene are not only in Vietnam but also in the world. Studies on the enterotoxin microbiology of two strains of suspected food poisoning bacteria $S$. argenteus (Tokyo13064 and Tokyo13069) in Japan [3]. Foodborne

\footnotetext{
${ }^{*}$ Corresponding author: thanhtran2710@gmail.com
} 
diseases cause increased mortality and morbidity in India with symptoms of intoxication and infection by various bacterial species like Clostridium, E. Coli, Botulism, Salmonella, and Staphylococcus [4].

The literature review shows that the bacteria noticed in contaminated food such as Salmonella, E.Coli, and Coliform received the most attention. According to research by Tran Cam Van (2005), Salmonella is a group of bacteria that cause intestinal diseases. Salmonella has good resistance to adverse conditions [5], can stay outside the body for a long time, and survives at $100^{\circ} \mathrm{C}$ for 5 minutes, at $60^{\circ} \mathrm{C}$ for $10-20$ minutes [6]. They can live for 2-3 weeks in soil or water, in ice for 2-3 months. In addition, E. Coli can live in warm milk, free of organic contamination [7]. Due to its wide distribution, E. Coli easily contaminates food from raw materials or water during production and processing. Especially with strong vitality will grow biomass very quickly, especially in an environment rich in nutrition.

The presence of pathogenic microorganisms in food will adversely affect human health. With a high density, when entering the body, there will be some reactions such as abdominal pain, fever, frequent bowel movements, discomfort; the usual solution is to buy self-medication. It risks creating an environment that makes resistance genes (ARGs) for pathogenic bacteria. A recent study by Tra Mi et al. (2017) also showed that the prevalence of ARGs resistance genes in Ecoli in septic tank sludge (domestic waste) in Ho Chi Minh City and Hanoi was very high [8]. It also showed found the level of growth of Ecoli ARGs in the human gut is actual and a catastrophic warning for an outbreak of this drug-resistant bacteria [9]. In particular, antibiotic resistance genes can be replicated by microorganisms in the same environment. Typically AR Salmonella originates in food animals and is transmitted through food to humans [10]. The mechanism of multiple drug resistance (MDR) in isolated Salmonella animal lines has been shown to involve portable genetic factors (MGE) such as the $\mathrm{IncA} / \mathrm{C}$ plasmid that can be transmitted between bacteria. Therefore, microbiological contamination in food is a considerable risk, when in Vietnam, antibiotics drugs are commonly sold at small pharmacies. The transfer of resistance genes through the food route will result in pathogenic microorganisms resistant to many antibiotics. It can lead to a disaster of food poisoning and severe gastrointestinal diseases.

Although food safety is serious, many sociological studies show that people's concern is not severe $[11,12]$. In this initial study, they assessed young people's interest in food safety and hygiene in beverages and tested the content of common pathogenic microorganisms in the research object. The " milk tea or bubble tea" - a popular drink in our country with the main ingredients being sugar, tea powder, milk cream, and other products, components such as flavors and stabilizers, was first sold by Taiwan in Taichung in the past 1980s and increasingly popular among young people [13]. In the past four years, dozens of international milk tea brands have entered the market in Ho Chi Minh City, such as Dingtea, Chago, Gongcha, Igongcha, Royal Tea, Tea Story, Toco Toco. Among those names, Taiwanese milk tea is the leading brand in this product- Hong Kong, Thailand, Japan, and Singapore milk tea [14]. In 2018, according to foody's statistics, spread across Vietnam, there were about 5,458 milk tea shops, of which Ho Chi Minh City alone accounted for 2,806. Besides the sweet aroma of milk tea cups, food safety and hygiene are a matter of concern. The quality and price of current milk tea vary depending on the brand in the market. Brand counterfeiting problems arising from illegal commercial interests will be sold at lower prices resulting in uncontrollable product quality. 


\section{Materials and research methods}

\subsection{Research area}

Through the chain of stores and the price of traditional milk tea (no topping), milk tea is divided into two types with the brand name (brand name) with the cost of over 35,000 VND (1.5 USD) and no brand name (no brand name). The study initially tested nine sample sites of milk tea and three ice samples at three branded milk tea shops with Table 1.

Table 1. Grouping and symbolizing store names

\begin{tabular}{|c|c|c|}
\hline Group & Sample classification & Sample code \\
\hline 1 & Branded milk tea & AG1, BL1, AU1, AT1 \\
& AK1 and AR1 \\
\hline 2 & Unbranded milk tea & C1, C2, and C3 \\
\hline
\end{tabular}

Ho Chi Minh City is the most significant economical center in Vietnam and in terms of population and scale of urbanization. Figure 1 shows the shops (branded milk tea) and mobile milk tea selling points in front of the school gate (non-brand milk tea) in two downtown districts.

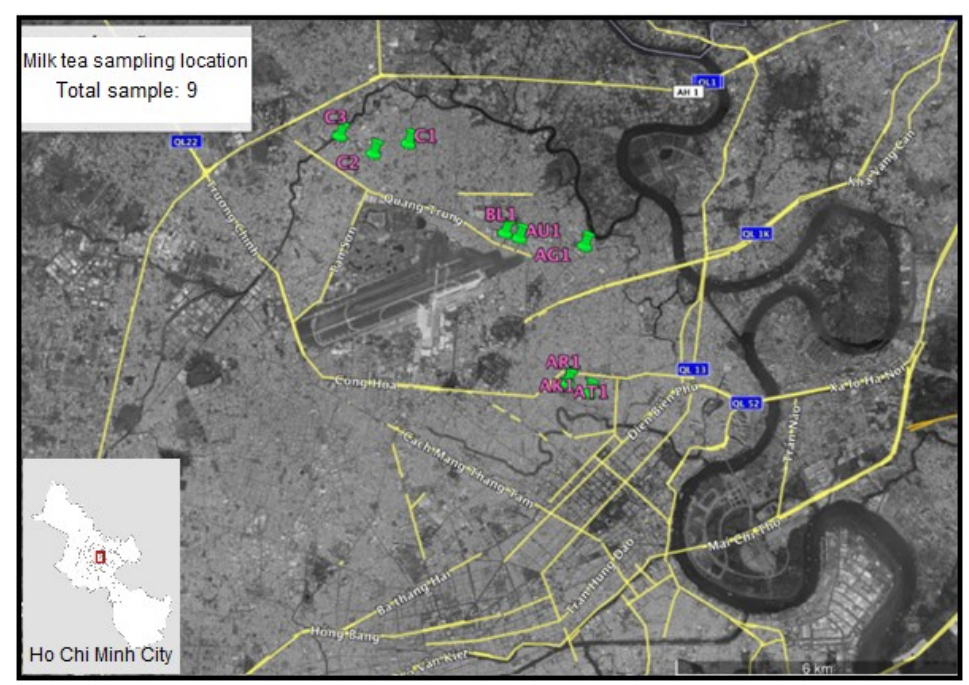

Fig 1. Map of sampling area in Ho Chi Minh City, Vietnam

The sample collection complies with Circular 16/2009/TT-BKHCN of the Ministry of Science and Technology on guiding the State inspection of the quality of goods circulating on the market and other relevant regulations of relevant laws.

\subsection{Research methods}

\subsubsection{Opinion assessment and survey method}

The survey process collected information from 100 face-to-face interviews with young people (18-25 years old). The contents focus on discussions about (1) the frequency of milk 
tea consumption, (2) views on food safety and factors to improve quality management, especially for the type of milk tea.

The data collected from the experimental treatments were entered and preliminarily processed by Excel 2016. Then, run statistics (frequency and description mean, standard deviation, max, min, One-way ANOVA) using SPSS 20.

\subsubsection{Microbiological analysis method}

Coliform and E. Coli Contamination content was analyzed using Scharlau specific medium based on TCVN 4884: 2005 (ISO 4833:2003), each sample was spread on three plates, and the results were averaged. According to the National Technical Regulations for Microbial Contamination in Food QCVN 8-3/2012/BYT and QCVN 10/2011/BYT on Instant Ice, the results are evaluated according to the contamination limit.

\section{Results and discussion}

\subsection{Evaluation of opinions and views on hygiene and safety of young people}

The initial study was conducted with experimental interviews on 50 meaningful questionnaires. The sex distribution includes 31 females (62\%) and 19 males (38\%). More than $90 \%$ of the survey sample belongs to the group of students, and the rest are office workers with the young age of 18 - 23 years old accounting for 94\%, the age group $24-29$ accounting for $4 \%$, the rest are over 30 years old. Total personal income (all sources or given) typical of the young age group, mostly students, is not high with $80 \%$ (40/50 votes) less than 3 million VND (130 USD)/month, income 3-7 million VND (130 - 300 USD)/month reaching $18 \%$ and over 15 million VND (640 USD) only $2 \%$.

The results of Figure 2 show that the level of milk tea consumption of the total sample is very high. The number of respondents who choose to drink regularly (2-3 times a week) accounts for $30 \%$ of the total and only $2 \%$. If you choose never, it can be seen that this drink is currently very interested by consumers. Interestingly, $80 \%$ of the votes have an income of less than 3 million VND/month, but $48 \%$ of the total sample spends a large amount of money, about 50,000 - 200,000 thousand VND (2 - 8 USD)/week, and 8\% spends about 200,000 - 500,000 VND (8- 20 USD)/week for spending on drinking milk tea. It shows that the surveyed subjects have a very high demand for milk tea when they are willing to spend 800,000 VND (32 USD) per month while total income is less than 170 per month.

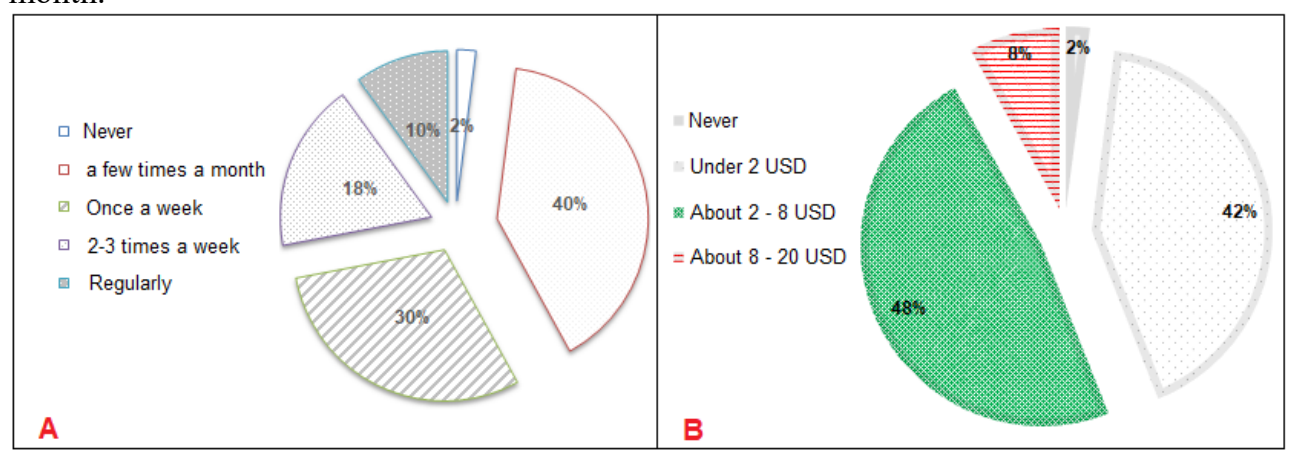

Fig. 2. Nitrogen (A) and total organic carbon (B) content of the treatments 
The issue of food safety and hygiene through the survey found that although consumers love food very much, they are still very concerned about health issues, $62 \%$ of the total votes are very interested in this issue, and only $2 \%$ of the polls did not pay attention. However, the number of disinterested comments also accounted for a significant number of $20 \%$ of the total votes. This shortcoming shows that not all consumers pay attention to clean and safe food.

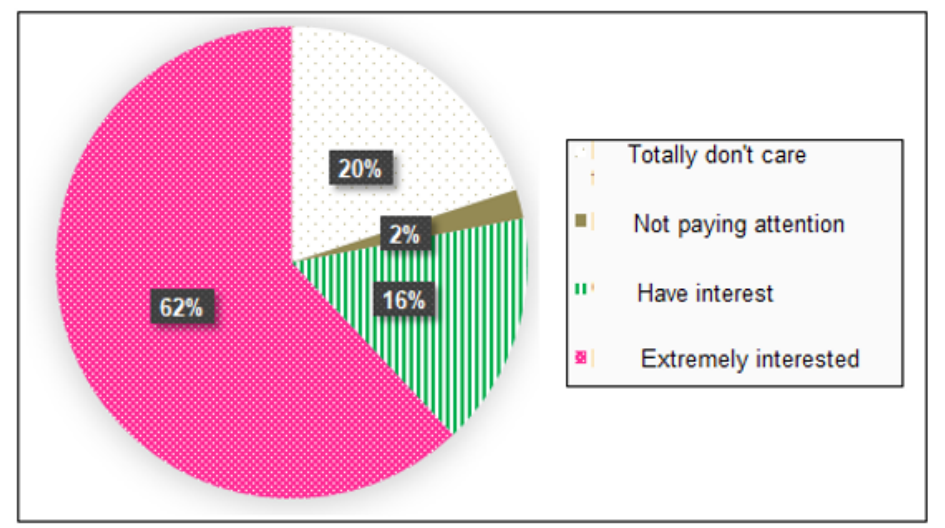

Fig. 3. Young people's interest in food safety and hygiene in milk tea

$58 \%$ of the voters agree that price will affect food safety and hygiene in milk tea, and $16 \%$ choose to disagree entirely. This statement can tell that consumers are most interested in the price of a product they buy. Many people believe that the higher the price brings to the better the food quality and vice versa. However, it can be seen that about $20 \%$ of the survey samples still believe that the price will not affect food safety and hygiene. In general, Figure 4 shows that consumers are most concerned about milk tea and food safety and hygiene in this drink. They agree that price level has a significant influence on food quality.

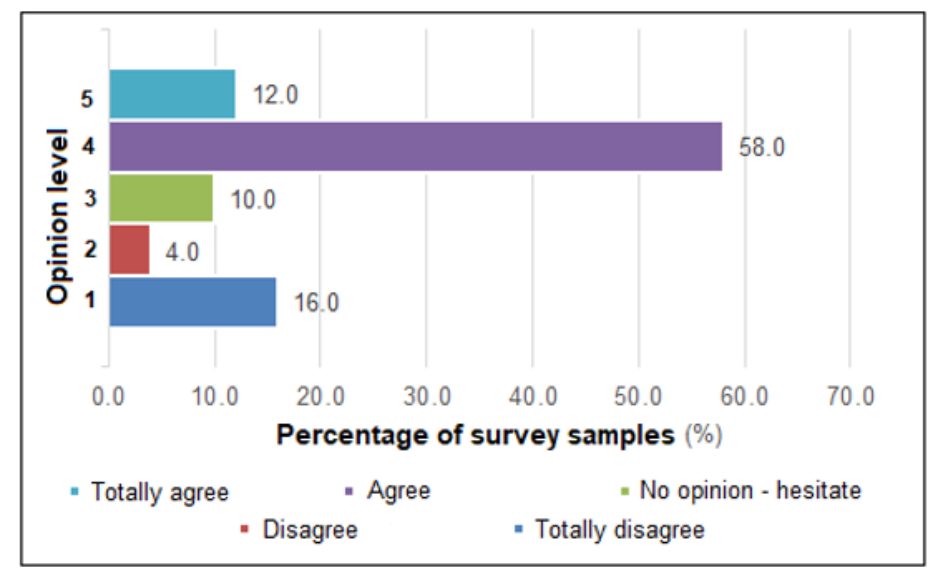

Fig. 4. The opinion of the surveyed on the price will affect food safety and hygiene in milk tea

Finally, when asked if they knew about food safety and hygiene standards, more than $80 \%$ of the total sample did not know. With the question about pathogenic microorganisms and their harmful effects, $70 \%$ of the surveyed people knew about Ecoli, 38\% knew about Coliform, but the number of candidates who did not know also accounted for a significant proportion of $28 \%$. It shows that the issue of food hygiene is concerned, but this knowledge is not so widespread. Increased publicity policies are essential to raising awareness and 
concern about food safety to protect consumers and establish a safe environment for street food.

\subsection{Evaluation of the existence of pathogenic microorganisms in milk tea}

The study was conducted with two groups of milk tea; each group will take milk tea samples with and without ice. Evaluation of 3 ice samples at three brand milk tea shops. The total number of survey samples collected was 21 samples.

Figure 5 shows that the overall Coliform variation in the two milk tea groups is considerable. Group 2 milk tea has the highest level of contamination, especially C 2 homemade milk tea shop with the highest pollution level. However, the group of branded milk tea with mandatory hygiene rules according to the brand chain also had a significant amount of Coliform.

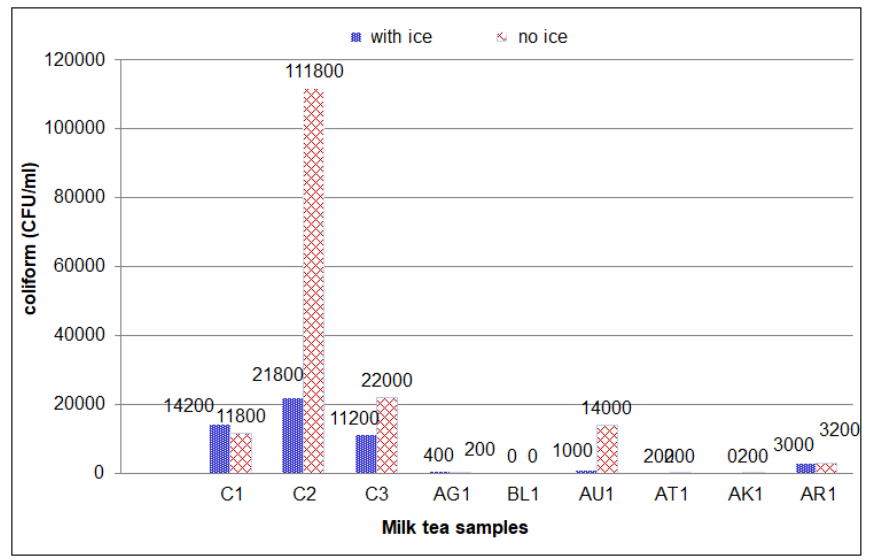

Fig. 5. The concentration of Coliform contamination in milk tea samples

Figure 6 shows that both milk tea groups had a significant amount of Ecoli, most notably the $\mathrm{C} 3$ milk tea sold in front of the school gate with high exposure of $1000 \mathrm{CFU} / \mathrm{ml}$ for the iced and non-ice samples of 600 . CFU/ml. One problem is that AR1 milk tea belonging to the branded milk tea group with a price of 40,000 - 60,000 (1.7 - 2.6 USD) is also contaminated with Ecoli with the non-ice sample.

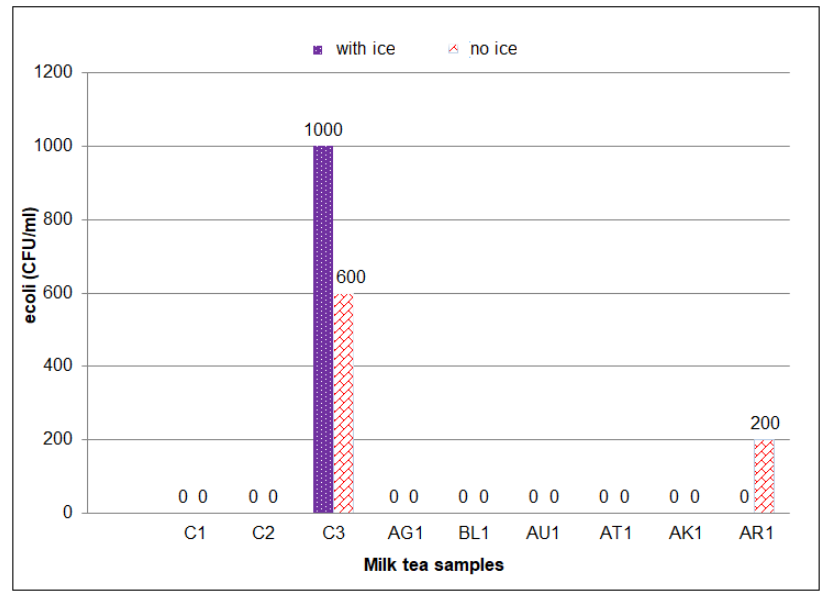

Fig. 6. The concentration of E.Coli contamination in milk tea samples 
In addition, ice is also an essential ingredient to create the deliciousness of milk tea. Three ice samples were collected at three stores with famous brands denoted AT1-ice, AK1-ice, and AR1-ice. Model AR1-ice is a brand from Hong Kong with a 30,000 - 50,000 thousand 1 cup price, relatively high compared to other milk teas. The quality problem and the source of raw ice are expected to be on top. However, the analysis showed that the Coliform concentration in the ice of this store was higher than that of the other two stores, reaching 6,800 $\mathrm{CFU} / \mathrm{ml}$. Ice samples from different brands also showed fewer coliform levels of 1157 and $2557 \mathrm{CFU} / \mathrm{ml}$. With E.Coli also shows that AE1-ice also gives an outstanding amount of 193 CFU. Compared with QCVN $10 / 2011$ of the Ministry of Health about instant ice, it is not detected, so it can be seen that the origin of ice is also a significant part of causing pollution in milk tea.

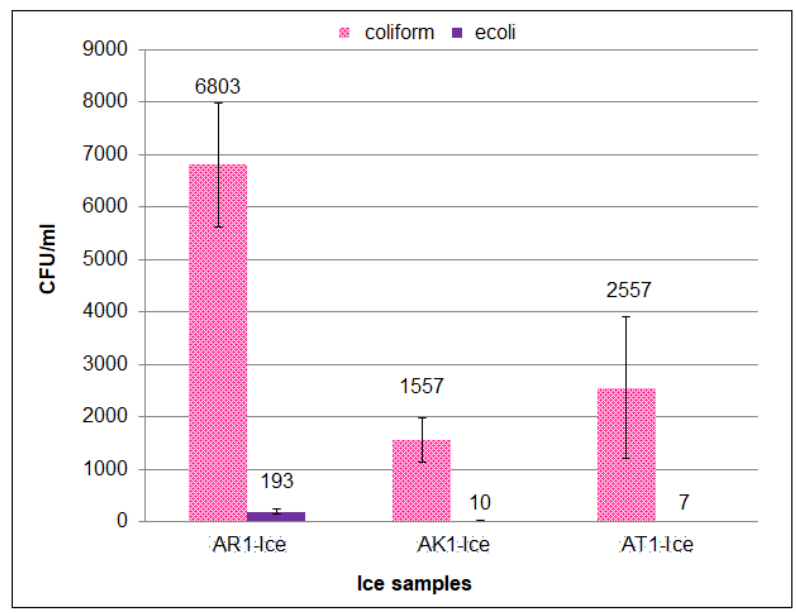

Fig. 7. The concentration of E.Coli contamination in milk tea samples

\section{Conclusion}

Milk tea (bubble tea) is known as one of the popular drinks, and the survey results with young people are incredibly personal when $30 \%$ of the surveyed people regularly drink, and more than $50 \%$ spend more than 50,000 VND ( $\sim 2$ USD)/week. However, sampling and analyzing the content of E.Coli and Coliform in 9 milk tea samples and three ice samples of the three famous brands above showed that there are microorganisms in milk tea (E. Coli and Coliform in $50 \mathrm{ml}$ of milk tea sample). Unbranded group milk tea had higher Coliform and E.Coli contamination levels than famous brand milk tea. The C3 milk tea sample had the highest Ecoli content with $1000 \mathrm{CFU} / \mathrm{ml}$ in the iced sample $600 \mathrm{CFU} / \mathrm{ml}$ in the sample without ice. The highest Coliform was C2 milk tea with 21,800 CFU/ml in the sample with ice and $111,800 \mathrm{CFU} / \mathrm{ml}$ without ice. The analysis of milk tea brands showed that pathogenic microorganisms and initial research showed that ice is also potentially one of the causes of microbial contamination of milk tea. Although the research needs to go through many steps to avoid microbial exposure and unwanted consequences, it is advisable to drink milk tea from reputable brands and limit its use in places where the roadside or the senses are affected. It is not hygienic, nor should you drink this drink too often or drink it many times a day.

We would like to thank Nguyen Tat Thanh University for supporting the time and facilities for this study. The project committee also thanks for the participation of student Dinh Thi Kim Hong, majoring in environmental and resource management, Nguyen Tat Thanh University. 


\section{References}

1. T.T.T. Hien, N. Van Duy, The University of Danang-Journal of Science and Technology. 15-18 (2020)

2. T. Dinh, Nearly 2,000 people were hospitalized, 8 died from food poisoning. Viewed from <https://laodong.vn/thoi-su/nam-2019-gan-2000-nguoi-di-vien-8-nguoi-chet-vingo-doc-thuc-pham-777973.1do>, Lao Dong Online magazine. (2020).

3. Y. Suzuki, H. Kubota, H.K. Ono, M. Kobayashi, K. Murauchi, R. Kato, A. Hirai, K., International journal of food microbiology. $262: 31-37$ (2017)

4. S. Khare, A. Tonk, A. Rawat, Int J Food Sci Nutrition. 3 : 9-10 (2018)

5. F. McDonough, R. Hargrove, 51: 1587-1591: (1968).

6. M.F.A. Omar, N.S. Abdul Manaf, S.N.N. Mohd Sufian, N. Zakaria, N.F.N. Ayub, S.F.A. Mohd Nawi, Z. Mohd Zain, Journal of Clinical and Health Science. 3 : 1-4 (2018)

7. Y. Huang, H. Chen, E, Food Control. 22: 1178-1183 (2011)

8. N.T. Mi, H.T. Giap, N.X. Binh, N.H.C. Dung, C., Journal of Science and Technology. 1 : 7-14 (2018)

9. G.C. Schutzius, Antibiotic Resistance in Septic Sludge and Receiving Environments of Ho Chi Minh City, Vietnam, (2018).

10. J.G. Frye, C.R. Jackson, Frontiers in microbiology. 4 : 135 (2013)

11. A. Liu, R. Niyongira, Food Control. 79 : 185-191 (2017)

12. A. Miri, M. Hami, A. Dargahi, M. Poursadeghiyan, M. Farrokhi, R. Ivanbagha, M.M. Khalesi, Health in Emergencies and Disasters. 3 : 91-96 (2018)

13. Fei Liu, Xujun Ye, Yong He, Li Wang, Journal of Food Engineering. 93: 127-133 (2009)

14. N. Do, A. Nguyen, Entering the Finnish food and beverage market: Case company: Gong Cha bubble tea brand, (2020). 